\title{
Analysis Efficiency Production and Strategies of Small-Medium Scale Enterprises
}

\author{
Dede Ruslan \\ Fakultas Ekonomi, Universitas Negeri Medan \\ Sumatera Utara, Indonesia \\ drasruslan@unimed.ac.id
}

\begin{abstract}
This research was aimed to analyze the factors that affect the level of production and efficient use of production factors on small and medium scale enterprises (SMEs), and to identify the internal and external factor to find strategic model alternative that can be applied by small and medium scale enterprises (SMEs) to develop their business. To achieve the objectives, we estimate the frontier production model to obtain technical efficiency with technical inefficiency determinants model. In this study, we adopt the translog production model in obtaining the technical efficiency scores and the linear technical inefficiency model to determine factors affecting the firms' inefficiency level and to find some strategic model used SWOT analysis. This study use survey and interview questionnaire technique which contain a series of questions for SMEs. Results showed that most variables, have signs as expected and most significant. The average level of technical efficiency (TE) for SMEs are 0.7832. Several economic factors that significantly affect technical inefficiency includes are quantity of labor, value of fixed asset, and for $\mathrm{TE}$ are the ratio of research and development expenditures to total expenditures of enterprises; ratio of information and communication technology and telecommunication expenditure; ratio of training expenses, but ratio of employees with education levels not significant. For strategis with SWOT analysis approach, the result indicated that SME's which have big potential to develop is ST strategy. According to this strategy, SME's should carry out product diversification by using technology, improve quality of product, and cooperate with suppliers to get supply raw material
\end{abstract}

Keywords: Technical efficiency, small and medium enterprises, frontier production model, SWOT analysis, Straregies.

\section{INTRODUCTION}

Many studies show that small and medium enterprises (SMEs) play a central role as the driving engine of growth, job creation and competitiveness in both domestic and global markets. SMEs also play a pivotal role in terms of innovation and productivity growth of a nation. Small- and medium-scale enterprises (SMEs) play a pivotal role in the socio-economic development and growth of nations. SMEs have greater economic benefits than large firms in terms of employment generation, efficiency, and growth since they use more of what a country posses and less of what it lacks. They are particularly important for developing countries not only because they demand more labour, but also because they usually use unskilled workers whose supply is in excess in these countries.
SME has contribution to economic growth, that is indicated by their contribution to employment and Gross Domestic Product. SMEs contribute to employment more than 99 per cent of national employment and contribute to more 52,55 per cent. Although the contribution of SMEs to national income in the Indonesian economy has been significant since they provide employment for more than 50 percent of all employed labour force and generate more than 50 percent of the manufacturing GDP, they are faced with a number of problems.

Nevertheless, the developing of SME's facing some problems namely lack of capital, difficulties in marketing, simple organizational structure with unstandard job description, low of quality management, limited human resource, generally it has no finanacial accounting, low of legality aspect, and low of technology quality.It is believed that small enterprise owners are not aware of the need or significance to analyse the internal and external business environment. Moreover, it is customary to find that most of them have no specific policies in conducting their businesses. Poorly planned growth and failure to foresee the stages of growth can pose a real problem for small enterprise owners.

The production efficiency is one of the most important problems of the present-day logistics, both at operational as well as strategic levels. Increasing the level of the efficiency of the production process can be achieved in many ways. One way which could be adopted by SMEs to overcome these problems is to improve internal efficiency. Improving technical efficiency could be an important means for SMEs to grow and expand in a liberalized and competitive environment. As resource constraints increase because of increased population and competition from the global economy, the potential to increase the level of production by bringing more resources into use becomes more and more limited and uneconomical.

The efficiency of an enterprise is measured by the ability to produce output with minimum cost or making maximum profit. The issue of technical efficiency (TE) that efficiency is the decision-making ability to produce to get the maximum output from a set of input (output oriented) or to produce output using the lowest amount of input (input oriented).[1] but the level of TE of a firm can be characterized by the relationship between the present and potential level of production [2]. TE differs from allocative efficiency (AE), 
which refers to the use of inputs at an optimal rate in order to achieve maximum profit.

The existence of technical inefficiencies in production has long been recognized since frontier efficiency analysis used to assess the technical and distribution efficiency; scale efficiency; and allocative efficiency [3]. Many different methods have been developed to analyses frontier efficiency. The most clear differences are in the use of boundary specifications (i.e., parametric or nonparametric); approaches in boundary computation (i.e., programming or statistical techniques); and the formula for the standard deviation from the frontier (i.e., inefficiency or a mixture of inefficiency and statistical disorder). Among these methods, the nonparametric approach to the analysis of the efficiency frontier is very attractive due to the minimum data requirements and its flexibility. Consequently, a significant body of empirical literature is currently devoted to the analysis of technical efficiency. Given the current changes in the global product and factor markets, and considering also the increased bifurcation of economic activities worldwide, the improvement of internal efficiency is a sine qua non for sustainable competitiveness in international markets.

The issue of efficiency is often associated with the quality of labor or human capital, which is often identified as the main input in production of output, and helping the process of economic growth. An increase in human capital investment through education and training will produce a more knowledgeable labor force. Human capital will improve labor quality and productivity; and ultimately improve the efficiency of manufacturing firms. Firms that have a high number of educated workers are able to maintain and control technologies and adapt to new technologies.[4] Labor quality is more able to make further investments in human capital, creating knowledge workers who are able to learn quicker and are more innovative [5], [6]. In fact, a decline in the proportion of skilled labour in a firm will reduce productivity. Further, the positive relationship between the length of the education of employees and productivity has been repeatedly proven [7]. The rationale is that education improves skills in people, while enabling them to be more innovative and think critically.

SMEs productivity levels can be enhanced either by improving technical efficiency and/or by improving technological application. A relevant question for SMEs policymakers is whether to pursue a strategy directed towards technological change (bringing new technologies) or a strategy towards efficiency (improving the use of existing technologies)[8]. The presence of shortfalls in production efficiency means that output can be increased without requiring additional conventional inputs and without the need for new technology. If this is the case, then empirical measures of efficiency are necessary in order to determine the magnitude of the gain that could be obtained by improving performance with a given technology. In the presence of technological gap, technical progress is the rational strategy to adopt to significantly increase SMEs production.

In this paper aims to attain two major objectives. The present study seeks to examine the extent and determinants of
TE of SMEs in Medan city North Sumatera and the second objective attempts to explain the strategies to improve performance SMEs in Medan city North Sumatera.

\section{METHODOLOGICAL FRAMEWORK AND EMPIRICAL LITERATURE}

\section{A. Methodological framework for Efficiency Production}

This study is based on the neoclassical theory of production. The neoclassical production theory provides a framework for modeling production functions in which it is assumed that the firm is operating on the frontier. In neoclassical theory of production, the primal production function defines the maximum possible output for combinations of inputs and technology. Farrell was the first to measure the productive efficiency in terms of frontiers and argues that economic efficiency should be divided into (a) TE, which measures the ability of a firm to maximize output using a given amount of input; and (b) Allocative efficiency (AE), which measures the ability of firms to use inputs at optimal proportions at a given price to produce certain level of output.

Empirical studies of productive efficiency have used a variety of approaches in modeling frontier production functions. Examples of such approaches include: parametric versus nonparametric; and deterministic versus stochastic methods [9], so the measurement of production frontier and efficiency can be classified into two groups:

- non-parametric model, known as the Data Envelopment Analysis (DEA) and

- Parametric model known as Stochastic Frontier Analysis (SFA)

The parametric approach distinguishes the effects of random shocks from the effects of inefficiency as it takes into account measurement errors and other noise in the data. The non-parametric assumes any deviation from the frontier is due to inefficiency [10]. This however, introduces a severe bias in efficiency measurement when production is subject to random shocks (noise) outside the firm's control. Secondly, they differ in the way the frontier function is imposed on the data. Parametric methods consider frontier production as a parametric function of the inputs and start from a particular function (e.g. Cobb-Douglas, CES, Translog). In the estimation of non-parametric functions, no previously defined form is imposed on the production function. Non-parametric estimation uses linear programming with no assumptions being made on the stochastic properties of the data [11]. The basic structure of the deterministic model is specified as:

$$
Y_{i}=f(X ; \beta) \exp ^{-u}
$$

where Yi represents the potential production level of the ith farm; $(\mathrm{X} ; \beta)$ i f is a suitable function (e.g., Cobb-Douglas or Translog); $\mathrm{Xi}$ is a vector of inputs of the ith farm; $\beta$ is a vector of parameters to be estimated; and $i$ is a non-random error term associated with the farm-specific factors which contribute to the ith farm not attaining maximum efficiency. One important limitation of the deterministic approach is that it does not allow for random errors. This implies that all the residuals are considered as inefficiency.[12] 
Normally, the stochastic production frontier model is used to estimate the TE. The estimated model is often based upon the Cobb-Douglas or translog production function. The present study uses a translog production function to analyse the production frontier. In general, a translog production function is expressed as follows:

$$
\begin{aligned}
& Y_{i}=\left(X_{i} \ldots \ldots . X_{n}\right) \text {. } \\
& =\alpha_{0} \prod_{i=1}^{n} X_{i}^{\alpha i} \Pi_{i=1}^{n} X_{i}^{1 / 2\left[\sum_{i=1}^{n} \beta_{i j} \ln X_{j}\right]}
\end{aligned}
$$

The tranlog stochastic production frontier model is as follows;

$$
\begin{aligned}
& \ln Y_{i}=\ln \alpha_{0}+\sum_{i=1}^{n} \alpha_{i} \ln X_{i} \\
& +\sum_{i=1}^{n} \alpha_{i} \ln X_{i}+1 / 2 \sum_{i=1}^{n} \sum_{i=1}^{n} \beta_{i j} \ln X_{i} \ln X_{j} \\
& +v-u_{i}
\end{aligned}
$$

where, $\mathrm{Y}$ is output, $\alpha$ is efficiency parameter, $\mathrm{Xi}, \mathrm{Xj}$ are inputs, vi is a random variable that is assumed to be independent and normally distributed, $\mathrm{N}(0, \sigma \mathrm{V} 2)$; and ui is a non-negative random variable which refers to the impact of inefficiency in the production of the firms. The variable is assumed to be independently distributed with truncation, $\mathrm{N}(0$, ou2) and $i$ is firm $i$

The efficiency of firms in the production of output can be achieved when a firm is able to produce output at the frontier level where the firm is at its best performance. Firms operating below the boundary are considered inefficient. The way to enhance efficiency is to improve the existing technology or enhance employee skills through education and training so that the existing technology can be used more efficiently.

The variance parameter for the model is written as follows:

$$
\sigma^{2}=\sigma_{v}^{2}+\sigma_{u}^{2} ; \lambda=\sigma_{u}^{2} / \sigma_{v}^{2} \text { and } \gamma=\sigma_{u}^{2} / \sigma^{2}
$$

where, parameter $\gamma$ having a value between zero and one. The $\lambda$ parameter could be any non-negative value. The value of TE for each firm is derived from the following formula:

$$
T E=\frac{Y_{i}}{\exp (x, \beta)}=\frac{\exp (x, \beta-u i)}{\exp (x, \beta)}=\exp (-u i)
$$

The index of TE is between zero and one or $0<T E i<1$. The manufacturer $i$ achieves maximum output if $T E i=1$.

The method of maximum likelihood (ML) estimation procedure is used for the frontier production model (equation 4). To determine the appropriateness of the frontier model, the value $\gamma$ is observed. If the value is large and significant, than frontier production model is better than the ordinary production model for analyzing firm production processes.[13]

\section{B. Management Strategy and SWOT AnalysisTheory}

Baron and Ensley, (2006) and Brockmann and Lacho (2010) say that entrepreuners are primarily concerned with recognizing opportunities and reizing the initiative.[14],[15]
An entrepreneur needs strategic management skill in addition to entrepreunerial skills to be able to survive in competitive environtment[16]. So that changes in market and the competitive strategies of large organizations have increased the pressure on SMEs to focus on innovation, innovation capabilities and innovation management[17],[18]. The assets and skill of the firm, which are the basis for competition, provide the foundation for sustainable competitive advantages. Competitive advantages can be achieved if SMEs choose the right business strategy is to first conduct the strategic management process [19]

Implementation of strategic management can increase competitiveness, reduce costs, improve decision-making, facilitate implementation of employee motivation system, shorten delivery times, higher quality of customer satisfaction, etc [20], [21]. The highlight a strong link between competitiveness and enterprise strategy. Highlighted the existence of a moderating effect of business strategy, especially in defender form, the cost and quality priorities influence positively [22]. The strategy is the process of creating a unique and valuable position with means of another set of activities. A strategy can be seen as a combination of activities. Strategy means creating connection in the activities of a firm. If there was only one ideal position, there would be no need of strategy. The essence of strategic positioning is: choose the activities that are different than those of the competitors.[23]

The internal and external factors most considerable for the company's future are referred to as strategic factors. In SWOT analysis, these factors are grouped into four parts called SWOT groups: strengths, weaknesses, opportunities, and threats. Strength refers to inherent abilities to complete and grow strong. Weaknesses are the inherent deficiencies that cripple one's growth and survival. Strength and weakness are mostly internal. Opportunities are the good chances and openings available for growth. These are environmental \& external. Threats are extremely wielded challenges, which might suppress inherent Strength, accelerate weakness and stifle with opportunities being exploited. These are again posed due to the external environment [24],[25]. SWOT analysis is one of the most respected and prevalent tool for strategic planning [26];[27]. By applying SWOT in strategic decisions, the purpose is to select or constitute and implement a strategy.

\section{RESEARCH METODOLOGY}

\section{A. Design Research Methodology}

Design reseach for the first cases, uses specification model for Efficiency Production with SFA production model and for the second cases uses SWOT analysis model to find out the strategies to improve performance SMEs in Medan city North Sumatera.

\section{B. Instrumentation}

A specially constructed questionnaire was developed and personally distributed to the respondents. The questionnaire consists of three parts. The first part consists of five questions enquiring the background and the performance of the enterprise. Such questions include type of business, number of 
employees, value of fixed asset, sales turnover, growth in sales, and an increase in the number of employees, total of research and development expenditures, total of information and communication technology expenditure, total expenditures of telecommunication, total of expenditure; total of training expenses, employees with education levels. The second part of the questionnaire sought to know of the enterprise owners practice towards strategic planning; such include whether the enterprise has a written mission statement and whether the enterprise has any person responsible for the strategic planning of the enterprise. The final part of the questionnaire consists of 40 items asking the enterprise owners about the strengths, weaknesses, opportunities, and threats of their businesses.

\section{Sample and Data Collection}

The scope of this study is limited to small enterprises that operate businesses in the city of Medan. In total, 50 SMEs enterprise owners participated as respondents in this study. The sampling method was based on convenient sampling. This study analyzed technical efficiency of SMEs using stochastic frontier production function approach. Convenient sampling procedure was employed to select 50 SMEs. Maximum likelihood estimation procedure was used to obtain the determinants of technical efficiency and technical efficiency levels of SMEs for the data collection.

For SWOT Analysis, a structured questionnaire survey and open-ended interviews are used as a technique for data collection. Literature review and discussion with managers from SMEs were used for developing the questionnaire. The questionnaire was divided into three sections:

1. The SMEs company background

2. SWOT factors i.e. Questions on the various factor considered under strength, Weakness, Opportunities and Threats.

3. Environmental factors, i.e questions on the various external factors affecting the performance of the SMEs

The structured questionnaires consist of five questions. For identifying the rank of various factors considered under Strength, Opportunity, Weakness, Threats and Environment and data is collected from the target market. Likert type five point scales were used.

\section{Analysis Data}

The study made use of stochastic frontier approach for the estimation of the technical efficiency level of SMEs as well as other variables influencing the inefficiency levels. Specification model for Efficiency Production with SFA production model, which is based upon the translog production function, is expressed as follows:

$$
\begin{aligned}
& \ln V A O_{i}=\beta_{0}+\beta_{1} \ln L+\beta_{2} \ln F A+0.5 \beta_{3}(\ln L)_{i}^{2} \\
& +0.5 \beta_{4}(\ln F A)_{i}^{2}+\beta_{5} \ln L_{i} \ln F A_{i}+v_{i}-u_{i} \ldots \ldots . .(5)
\end{aligned}
$$

where VA is SMEs value added Output; L is quantity of labor, FA is value of fixed asset; $\mathrm{i}$ is SMEs ith and $v$ and $u$ are error terms.
The estimation for determinants of TE using the ML procedure with specification model are expressed as follows :

$$
\begin{aligned}
& \text { TIE }_{i}=\beta_{0}+\beta_{1} \ln \text { RRDTE }_{i}+\beta_{2} \ln \text { RICTTTE } \\
& +\beta_{3} \ln \text { RTE }_{i}+\beta_{4} \text { RELUS }_{i}+\beta_{4} \text { REBLUS } \\
& +v_{i}-u_{i}
\end{aligned}
$$

where TIE is the technical inefficiency derived through SFA approach; RRDTE is the ratio of research and development expenditures to total expenditures; RICTTTE represents the ratio of information and communication technology (ICT) and telecommunication expenditure; RTE is the ratio of training expenses; RELUS is the ratio of employees with education levels of Under Graduate and Senior High Scholl; REBLUS is the ratio of workers with education levels below the Under Graduate and Senior High Scholl level.

Analysis data for SWOT Analysis uses internal strategy matrix (IFAS) and external (EFAS) to formulate weighting, rank, and score each item contained in the strength (S), weaknesses $(\mathrm{W})$, opportunities $(\mathrm{O})$ and threats $(\mathrm{T})$

\section{RESULTS AND DISCUSSION}

\section{A. Efficiency Production used SFA production model}

The maximum likelihood estimates of the parameters of the model obtained from estimating the stochastic frontier production function and the level of technical inefficiencies of the SMEs are presented and discussed in this section. The

\begin{tabular}{|c|c|c|}
\hline Variable & Coefficient & t-statistic \\
\hline $\mathrm{C}$ & 94.85665 & $4.101737 * * *$ \\
\hline LOG(L) & 1.770705 & $9.713350 * * *$ \\
\hline LOG(FA) & -12.45325 & $3.904462 * * *$ \\
\hline $0.5^{*}\left(\mathrm{LOG}(\mathrm{L})^{\wedge} 2\right.$ & -1.887945 & $-2.314038 * *$ \\
\hline $0.5^{*}(\mathrm{LOG}(\mathrm{FA}))^{\wedge} 2$ & 0.760979 & $3.463128 * * *$ \\
\hline LOG(L)*LOG(FA) & 0.296081 & $2.420708 * *$ \\
\hline \multicolumn{3}{|c|}{ Determinants of Technical Inefficiency } \\
\hline $\mathrm{C}$ & -0.725123 & -0.873739 \\
\hline LOG(RRDTE) & -0.365432 & $-3.873734 * * *$ \\
\hline LOG(RICTTTE) & -0.265325 & $-5.982327 * * *$ \\
\hline LOG(RTE) & 0.153039 & $1.987635^{*}$ \\
\hline LOG(RELUS) & 0.122324 & 0.112232 \\
\hline LOG(REBLUS) & 0.563525 & 1.004383 \\
\hline sigma-squared & 0.973272 & $7.927327 * * *$ \\
\hline gamma & 0.628227 & $34.87263 * * *$ \\
\hline Log Likehood & \multicolumn{2}{|l|}{-1928.987373} \\
\hline LR test of the one-sided error & \multicolumn{2}{|l|}{128.987297} \\
\hline
\end{tabular}
results of the production function estimated using the ordinary least squares technique are reported in table 1.

TABLE I. MAXIMUM LIKELIHOOD ESTIMATES FOR THE PARAMETERS OF THE C-D STOCHASTIC FRONTIER PRODUCTION FUNCTION

Note: $*$ significant at $10 \%$, ** significant at $5 \%$, *** significant at $1 \%$.

Source: Authors' computation estimated using the FRONTIER version 4.1 computer program developed by Coelli (1994).

Table 1 present the simultaneous estimation results for the production frontier models and technical inefficiency determinants for the SMEs. In Table 1, it is shown that the 
estimate for the value of gamma as parameter in the stochastic frontier production function is is quite large and significant at $1 \%$ significance level, which implies that the deviation from the production frontier is due to technical inefficiency, so the inefficiency effects are highly significant in the analysis of the technical efficiency of the SMEs.

The quantity of labor is positively significant, the capital input is negatively significant. The significant determinants of technical inefficiency for the SMEs are expenditure on R\&D, ICT and training, in which the increase in these expenditures will reduce the technical inefficiency in SMEs and ratio of technical and general workers will increase technical inefficiency. On the other hand, the ratio of the workers with level of education does not significantly affect SMEss technical inefficiency.

This clearly implies that technical efficiency increases as a SMEs are expenditure on R\&D, ICT and training. Secondly, it clearly demonstrates the important role expenditure on $R \& D$, ICT and training in enhancing SMEs output. Hence all negative signs must be converted to positive for their relationship to technical efficiency or vice versa [28]. The estimated coefficient for SMEs (R\&D; ICT) in the technical inefficiency effects model is significant and negative, implying that SMEs are technically efficient and able to benefit from economies of scale [29],[30]

Training workers with skills to perform a wide variety of tasks and to upgrade job skills as new technologies are introduced have positiv sign. It means that worker training plays a key role in adapting, modifying, and improving new technology. Meanwhile, investment in equipment and new technology may enable output per worker to increase. Results from the analysis indicate that research and development expenditures (RD) and training expenditures (TR) contribute positively to technical efficiency in overall SMEs. These findings are in line with previous studies by Batra \& Tan [31], $\mathrm{Ng} \& \mathrm{Li}$ [32], and Deraniyagala [33].

For the micro enterprises, the impact on efficiency level by increasing the training and $R \& D$ expenditures are found to be higher as compared to small \& medium sized enterprises. However, the coefficient of RD for small \& medium sized enterprise $s$ is not statistically significant. It is expected that the higher the level of labor quality, the more efficient will be both the use of existing technology and the absorption of new technology, which will consequently result in higher efficiency levels [34], [35]

The estimated coefficients for ratio of employees with the education level below SPM to the total workers (ED) in the technical inefficiency effects model are positive and highly significant at the $1 \%$ level of significance for SMEs. This implies that by increasing the unskilled labor ratio will deteriorate the technical efficiency, the negative impact on efficiency level by increasing unskilled labor ratio is relatively higher as compared to small \& medium sized enterprises.

Examining the distribution of technical efficiencies would indicate whether there exists any scope for improvement in the technical efficiencies of SMEs. The distribution of the technical efficiencies for the sample of SMEs are predicted and presented in table 2 .

TABLE II. DISTRIBUTION OF TECHNICAL EFFICIENCY OF SMES IN MEDAN CITY NORTH SUMATERA

\begin{tabular}{|l|l|}
\hline \multicolumn{1}{|c|}{ Efficiency range } & $\begin{array}{c}\text { Number/ } \\
\text { percent of SMES }\end{array}$ \\
\hline$<40$ & $9(0,18)$ \\
\hline $0.41-0.50$ & $6(0,30)$ \\
\hline $0.51-0.60$ & $9(0.48)$ \\
\hline $0.61-0.70$ & $6(0,60)$ \\
\hline $0.71-0.80$ & $15(0,90)$ \\
\hline $0.81-0.90$ & $3(0,96)$ \\
\hline $0.91-1.00$ & $1(1,00)$ \\
\hline $\begin{array}{l}\text { Numbers of } \\
\text { enterprises }\end{array}$ & 50 \\
\hline
\end{tabular}

Source: Author's computation

The estimated technical efficiency scores for the sampled SMEs range from less than 40 percent to more than 90 percent, with a sample mean technical efficiency level of 78,32 percent, so the average level of technical efficiency (TE) for SMEs are 0.7832 .

\section{B. Strategies to improve performance SMEs in Medan city North Sumatera}

Model analysis for the strategies to improve performance SMEs in Medan city North Sumatera used SWOT Analysis. Based on the results obtained recapitulation of respondents rating the factors that have been identified and grouped into two parts, namely the International Strategy Matrix Analysis Summary (IFAS) and External Strategy Matrix Analysis Summary (EFAS). Internal strategy matrix (IFAS) and external (EFAS) is used to formulate weighting, rank, and score each item contained in the strength (S), weaknesses (W), opportunities $(\mathrm{O})$ and threats $(\mathrm{T})$. Data processing results can be seen as the IFAS and EFAS table 3 and 4.

TABLE III. INTERNAL FACTOR ANALYSIS SUMMARY

\begin{tabular}{|c|c|c|c|}
\hline Internal Strate $g$ Factors. & Weight & Rsnk & Sorare \\
\hline \multicolumn{4}{|l|}{ Strengths (S) } \\
\hline a hicoguate workforce & 0,15 & 3 & 0,54 \\
\hline 2. Coopetatiot among businessoacple & 0,10 & 3 & 0,30 \\
\hline Q. Slules ease ir obta nurg rawi ma:enal & $(1,1)$ & 4 & 0,58 \\
\hline f. Shated cisioc enong businessoecple & 0,02 & 4 & 0.12 \\
\hline e. Invorticn and creative incustries & $0.0:$ & 3 & 0.15 \\
\hline f These spesiality orod whts more waroves tymes & $00 \%$ & 4 & 032 \\
\hline Sus Troal & 6,61 & & 2,11 \\
\hline \multicolumn{4}{|l|}{ Wcakncss (W) } \\
\hline 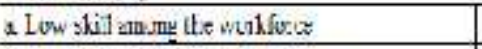 & 0,10 & 1 & 0,16 \\
\hline a. Lack of fac litias anc inffastructures & $0,0 \vdots$ & 1 & 0,08 \\
\hline 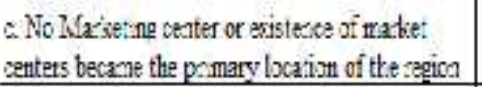 & $0,0 \vdots$ & 2 & 0,10 \\
\hline d. Shared cis:or anong businessazople & 0,10 & 1 & 0,10 \\
\hline Sus To:d & 6,39 & & 0,44 \\
\hline Iutal & 1,00 & & 2,35 \\
\hline
\end{tabular}

Source: Author's computation 
TABLE IV. EXTERNAL FACTOR ANALYSIS SUMMARY

\begin{tabular}{|c|c|c|c|}
\hline $\begin{array}{l}\text { External Strategy Factors } \\
\text { Opportunittes (O) }\end{array}$ & Weight & Rank & Secore \\
\hline $\begin{array}{l}\text { a. Tye arspo:t of echcation irst tutions to merove } \\
\text { 5.MEs }\end{array}$ & 0,12 & 4 & 0,48 \\
\hline b. H:gl: sornume intzeat & 0,07 & 2 & 0,21 \\
\hline = Promotion and market ng & 2,03 & 2 & $c, 08$ \\
\hline 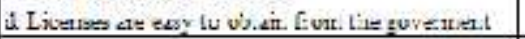 & 0,02 & 2 & $c, 00$ \\
\hline S ro To:al & 0,24 & & 0,83 \\
\hline \multicolumn{4}{|l|}{ Threats (I) } \\
\hline 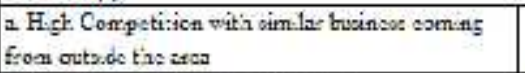 & 0,25 & 1 & 0,25 \\
\hline 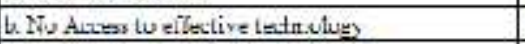 & 0,15 & 2 & 0,30 \\
\hline E. Lack of ontification for prodis: qualty & 0,20 & 2 & 0.40 \\
\hline A Contalipation efthents are still 1.mated & 0,15 & 1 & 1,16 \\
\hline $30 b$ To:2t & 0,75 & & 1,11 \\
\hline Iotal & 1,03 & & 1.94 \\
\hline
\end{tabular}

Source: Author's computation

These internal and external factors results are used to determine the coordinates of strategies to improve performance SMEs in Medan City North Sumatera (Figure 1). The horizontal axis $(\mathrm{X})$ is internal factors, while the vertical axis (Y) is external factors. Coordinate values of $\mathrm{X}=(2,11$ $0,44)=1,67$ and the value of $Y=(0,83-1,11)=-0,29$.

Fig. 1. Matrix SPACE position SMEs in Medan City North Sumatera (Source: Calculated by the author)

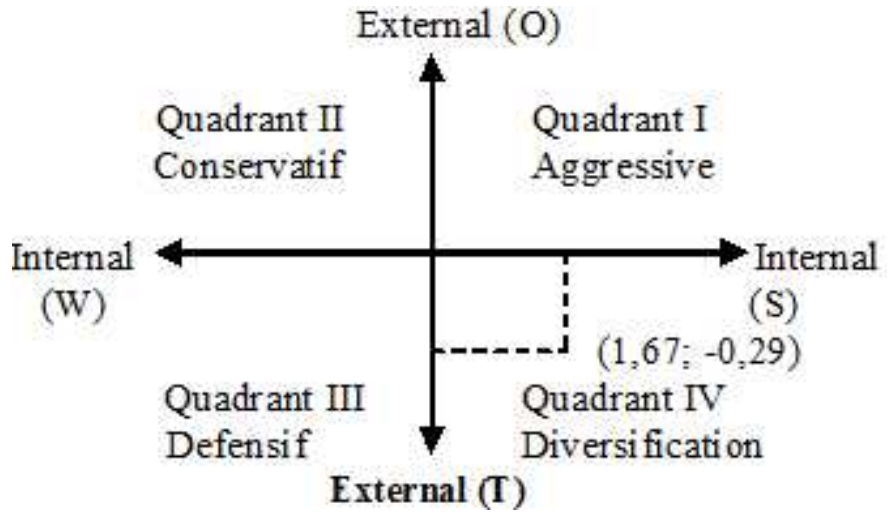

Source: Author's computation

The result showed that the grand strategy is in quadrant IV with the coordinates $S(1,67 ;-0,29)$, which means the strategy ST (Strength Threat) or an Diversification strategy. In the diversification strategies which will be applied based on the utilization of existing strengths in order to minimize the existing threat in SMEs management by using technology, improve quality of product, and cooperate with suppliers to get supply raw material.

These findings are in not line with previous studies by Rahayu Puji Suci.[36] that a strategic management analysis results show the development of small and medium enterprises in Gresik is located in Quadrant I, or should do or Aggressive Growth Strategy supports an aggressive growth policy (growth oriented strategy)

\section{CONCLUSIONS}

The paper have two examines, first is examine the TE scores for the SMEs in Medan City North Sumatera and identifies the determinants of technical inefficiency for these SMEs. Second is examine the strategies to improve performance SMEs in Medan city North Sumatera used SWOT Analysis.

The results show that the improving internal efficiency is one of the most important avenues for increasing performance SMEs. In this study, TE is at the higher efficiency with the average level of technical efficiency (TE) for SMEs are 0.7832. Several economic factors that significantly affect technical inefficiency includes are quantity of labor, value of fixed asset, and for TE are the ratio of research and development expenditures to total expenditures of enterprises; ratio of information and communication technology and telecommunication expenditure; ratio of training expenses, but ratio of employees with education levels not significant.

For to improve performance SMEs in Medan city North Sumatera used SWOT Analysis, in this study showed that the grand strategy is strategy ST (Strength Threat) or an Diversification strategy. In the diversification strategies which will be applied based on the utilization of existing strengths in order to minimize the existing threat in SMEs management by using technology, improve quality of product, and cooperate with suppliers to get supply raw material.

\section{Acknowledgment}

We are very grateful to Goverment of Medan City North Sumatera; Rector of State University of Medan, Director of graduate Program Study; Enterpreneur SMEs as a responden in this study.

\section{References}

[1] Kizito K. Mwajombe \& Malongo R. S. Mlozi, Measuring Farm-level Technical Efficiency of Urban Agriculture in Tanzanian Towns: The Policy Implications; World Journal of Social Science Vol. 2, No. $1 ; 2015$, p66

[2] Herrero, I., \& Pascoe, S.. Estimation of technical efficiency: a review of some of the stochastic frontier and DEA software. Computers In Higher Education Economics Review (CHEER), from http://www.economics.ltsn.ac.uk/cheer.htm, 2002, p1-11

[3] Farrell, M.J. , The measurement of productive efficiency. Journal of Royal Statistical Society Series A (General), 1957; 120, p253-281.

[4] Rahmah Ismail \& Idris Jajri,Sumbangan perubahan teknologi terhadap pertumbuhan output industry skel kecil dan sederhana di Malaysia. International , Journal of Management Studies, 2009, 16 (1): p39-61

[5] Bishop, J.H, Job performance, turnover and wage growth, Journal of Labour Economics,1990, Vol.8, p363-386

[6] Chapman, B.J. \&. Tan, H.W, An analysis of youth training in Australia, : Technological change and wages, Working Paper, Australian National University, 1990; p85.

[7] Black, S.E., \& Lynch, L.M., Human capital investment and productivity. The American Economic Review, , 1996; 86 (2), p263-268.

[8] Nkamleu, Guy Blaise, Productivity Growth, Technical Progress and Efficiency Change in African Agriculture". Africa Development Review, 2004, No16, vol.1, p203-222, Blackwell Publishing Ltd, Oxford, UK. 
[9] Xu, X., and Jeffrey, S.R., Efficiency and Technical Progress in Traditional and Modern Agriculture: Evidence from Rice Production in China. Agricultural Economics, 1998; 18: p157-165

[10] Iraizoz, B., Rapun, M., and Zabaleta, I, Assessing the Technical Efficiency of Horticultural Production in the Navarra, Spain. Agricultural Systems,2003, 78: p387-403.

[11] Apezteguia, B.I., and Garate, M.R. . Technical Efficiency in the Spanish Agrifood Industry. Agricultural Economics,1997, 17: p179-189.

[12] Battese, G.E., and Coelli, T.J. A model for Technical Efficiency Effects in a Stochastic Frontier Production Function for Panel Data. Empirical Economics, 1995, 20:p325-332

[13] Coelli, T. J. A Guide to FRONTIER Version 4.1: A Computer Program for Stochastic Frontier Production and Cost Function Estimation. Armidale: Department of Econometrics, University of New England CEPA Working Paper,1996, No. 7/96. P1-33

[14] Baron, R. A., \& Ensley, M. D. Opportunity Recognition as the Detection of Meaningful Patterns: Evidence from Comparisons of Novice and Experienced Entrepreneurs. Management Science,, 2006, 52: p13311344.

[15] Brockmann, E. \& Lacho, K. (2010). Strategic Planning: A Practical Primer for the Entrepreneur. The Entrepreneurial Executive,, 2010, 15, p25-32.

[16] Ireland, R. D. Strategy vs. Entrepreneurship. Strategic Entrepreneurship Journal, 2007, 1(1-2): p7-10.

[17] McAdam, R., Keogh, K., Transitioning towards creativity and innovation measurement in SMEs. Creativity and Innovation Management 13,2004 (2), p126-141

[18] Hotho, S., K. Champion. 2011. Small businesses in the new creative industries: innovation as a people management challenge. Management Decision, 2011, 49(1) p29-54.

[19] Kraus, S., Harms, R. \& Schwarz, E. J. Strategic planning in smaller enterprises-new empirical findings. Management Research News,2006, 29(6), p334-344

[20] Holatova, D., \& Brezinova, M., "Basic characteristic of small and medium sized enterprises in term of their goals", International Journal of Business and Social Science,2013, 4(15), p98-104.

[21] Tenai, J, K., Bitok, J, K., Cheruiyot, T, K., \& Maru, L, K., "Moderating variabel on SME's Strategies and competitiveness for international trade: a survey of horticultural trader in urban and peri-urban areas in Kenya”, International Business and Economic Research Journal,2009, 8(12), p105-116.

[22] Oltra, M, J., \& Flor, M, L., , "The moderating effect of business strategy on the relationship between operations strategy and firm's results", International Journal of Operations and Production Management,2010' 30(6), p612-638.
[23] Porter, M, E.,Towards a dynamic theory of strategy", Strategic Management Journal, 1991, 12, p95-117.

[24] Porter, M.E. (1996). What is strategy? Harvard Business Review, NovDec, pp 61-78

[25] S. D. Kalpande and , R. C. Gupta, M.D. Dandekar, A SWOT analysis of small and medium scale enterprises implementing total quality management, International Journal of Business, Management and Social Sciences Vol. 1, No. 1, 2010, pp. 59-64

[26] Glaister, K.W., and Falshaw, J.R. , Strategic planning still going strong. Long Range Planning, 1999, 32(1), pp. 107-16.

[27] Helms, M.M., and Nixon, J. Exploring SWOT analysis - where are we now?: A review of academic research from the last decade. Journal of Strategy and Management,2010,3(3), pp. 215-251

[28] Charoenrat, T. \& Harvie, C. (2012). Technical efficiency performance of Thai manufacturing small and medium sized enterprises. Proceedings of the 41st Australian Conference of Economists, Melbourne: Victoria University, 2012, p1-29.

[29] Phan, P. (2004). Trade liberalisation and manufacturing performance in Thailand 1990-2000. School of Economics, Faculty of Commerce, University of Wollongong,(Ph.D. thesis),2004,p198-208

[30] Le, V. \& Harvie, C., Firm performance in Vietnam: Evidence from manufacturing small and medium enterprises. Economic Working Papers, School of Economics University of Wollongong, 2010, p 6-34

[31] Batra, G. \& Tan, H., SME technical efficiency and its correlates: Crossnational evidence and policy implications. Washington, World Bank Institute, 2003, p1-32

[32] Ng, Y. C. \& Li, S. K. (2003), Training \& productive efficiency in transition economies.Oxford Economic Paper, 55, p607-624.

[33] Deraniyagala, S, The impact of technology accumulation on technical efficiency: An analysis of the Sri Lankan clothing and agricultural machinery industries. Oxford Development Studies, 2001, 29 (1),p101114.

[34] Mahadevan, R \& Mansor Ibrahim. Competitiveness and workforce status in the Malaysian micro-electronics sector. East Asian Development Network (EADN) ,2007, Working Paper No. 30, p1-29

[35] Zahid, Z.,\& Mokhtar, M. (2007). Estimating technical efficiency of Malaysian manufacturing small and medium enterprises: A stochastic frontier modelling. The 4th SMEs in a global economy conference, 2007, p 9-10

[36] Rahayu Puji Suci., Analysis Strategy for Small and Medium Business Development Policy Gresik District in East Java, IOSR Journal of Business and Management (IOSR-JBM) e-ISSN: 2278-487X. Volume 8, Issue-1 (Jan.-Feb. 2013), P01-09 